\title{
Feto Maternal Outcome of Teenage Pregnancy
}

Dr. Binoy Krishna Golder ${ }^{1 *}$, Dr. Most. Zakia Sultana ${ }^{2}$, Dr. Mahbubur Rahman ${ }^{3}$, Dr. Begum Shamsun Nahar Shirin ${ }^{4}$

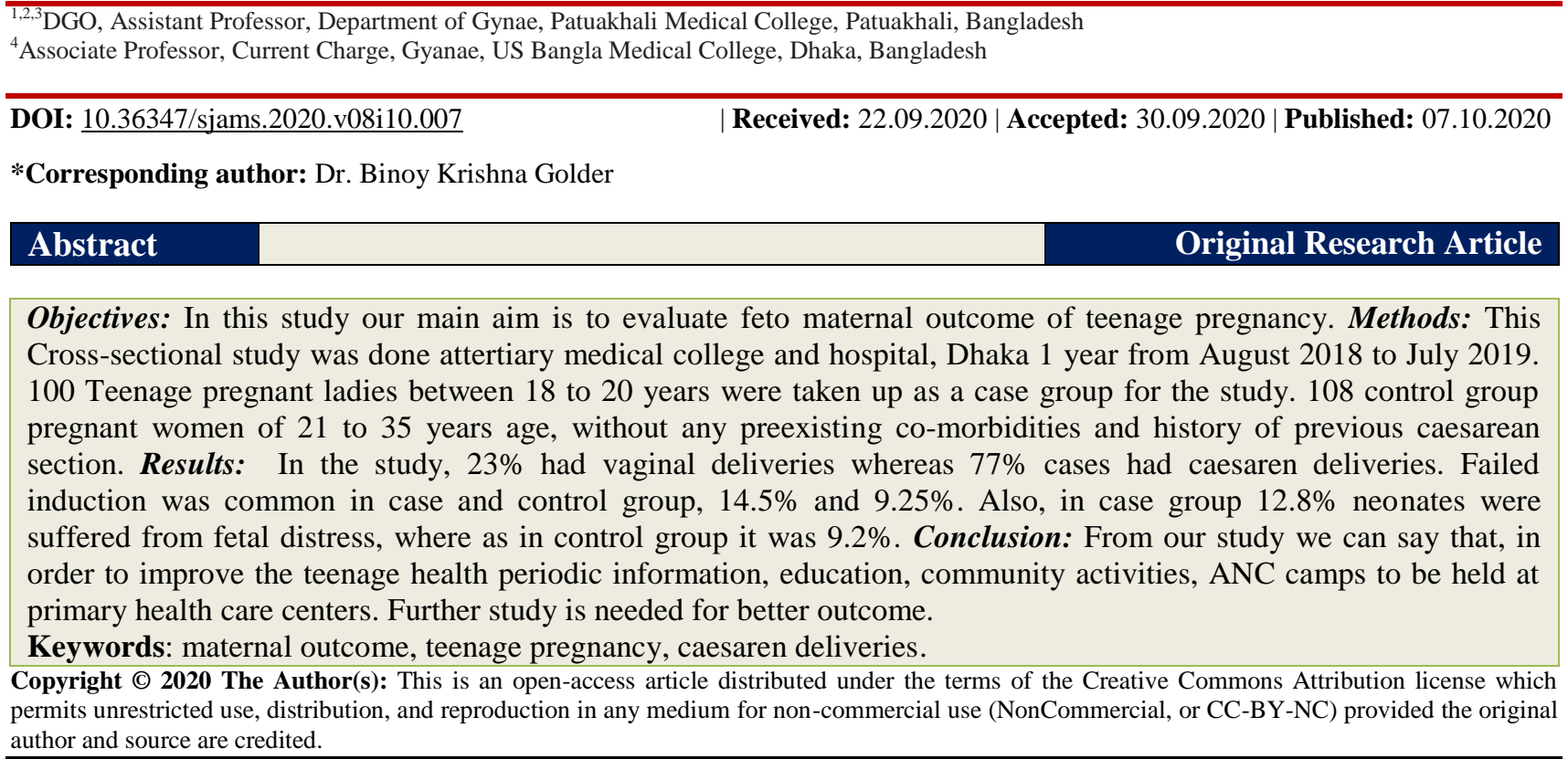

\section{INTRODUCTION}

In recent decade, adolescent pregnancy has become important health issue in a great number of countries, both developed and developing [1].WHO defines teenage pregnancy as any pregnancy from a girl who is 10 to 19 years of age, age being defined as her age at the time of delivery [2]. Adolescent pregnancy rate is on rise, emerging as serious problem all over the world and more so in developing countries like India. It constitutes 11 percent of all the births worldwide and 23 percent of overall disease burden due to pregnancy and child birth due to improper prenatal care needed for monitoring of maternal and fetal development.

The incidence of teenage pregnancy varies dramatically between the different countries, of which 90 percent is contributed by developing countries [3]. Nevertheless teenage pregnancy and delivery rate is significantly less in developed countries compared to developing countries [4].

Incidence of teenage pregnancy in India is 2 women out of every 1000 pregnancies. ${ }^{5}$ Teenage pregnancy is associated with series of maternal and fetal complications. Anaemia, pre-eclampsia, eclampsia, preterm delivery, instrumental delivery, increased LSCS rate due to cephalopelvic disproportion and fetal distress are strongly associated maternal complications in teenage pregnancy.

In this study our main objective is to evaluate feto maternal outcome of teenage pregnancy in a Bangladesh

\section{OBJECTIVE \\ General objective}

- In this study our main goal is to assess feto maternal outcome of teenage pregnancy in a Peripheral Military Hospital.

\section{Specific objective}

- To identify Total number of deliveries.

- To detect complications associated with teenage pregnancy. 


\section{Methodology}

\begin{tabular}{|l|l|}
\hline Type of study & Cross sectional study. \\
\hline Place of study & Tertiary medical college and hospital. \\
\hline Study period & 1 year from August 2018 to July 2019 \\
\hline Study population & Teenage pregnant ladies between 18 to 20 years were taken up for the study \\
\hline Sampling technique & Purposive \\
\hline
\end{tabular}

\section{Method}

- During the study, during this period, all cases were included in the study, irrespective of their booking and unbooking statuses after 28 weeks of pregnancy. 100 Teenage pregnant ladies between 18 to 20 years were taken up as a case group for the study. 108 control group pregnant women of 21 to 35 years age, without any preexisting co-morbidities and history of previous caesarean section.

- In the study, detail history of the patient has been taken in a prescribed data sheet with the informed consent of the patient or from the patient's guardian.Data collected regarding mode of delivery, whether vaginal delivery or caesarean delivery, full term vaginal delivery or preterm delivery, if LSCS then indication for LSCS, fetal outcome in terms of prematurity, RDS, low birth weight, still birth, anomalous fetus, NICU admission.

\section{Data analysis}

- Statistical analysis was performed using the Statistical package for social science SPSS version 15.0. A descriptive analysis was performed for clinical features and results were presented as mean \pm standard deviation for quantitative variables and numbers (percentages) for qualitative variables.

\section{RESULTS}

In table-1 shows total number of deliveries where number of total baby's delivered-892. Whereteenage pregnancy was 100 (11.21\%). The following table is given below in detail:

Table-1: Total number of deliveries

\begin{tabular}{|l|l|l|}
\hline Total Number of deliveries & Teenage pregnancy & More than 20 years pregnancy \\
\hline 892 & $100(11.21 \%)$. & $118(88.79 \%)$ \\
\hline
\end{tabular}

In figure-1 shows educational status of the study group where in case group most of the patients completed only their SSC, no one completed their masters where as in control group 7 people completed their masters. The following figure is given below in detail:

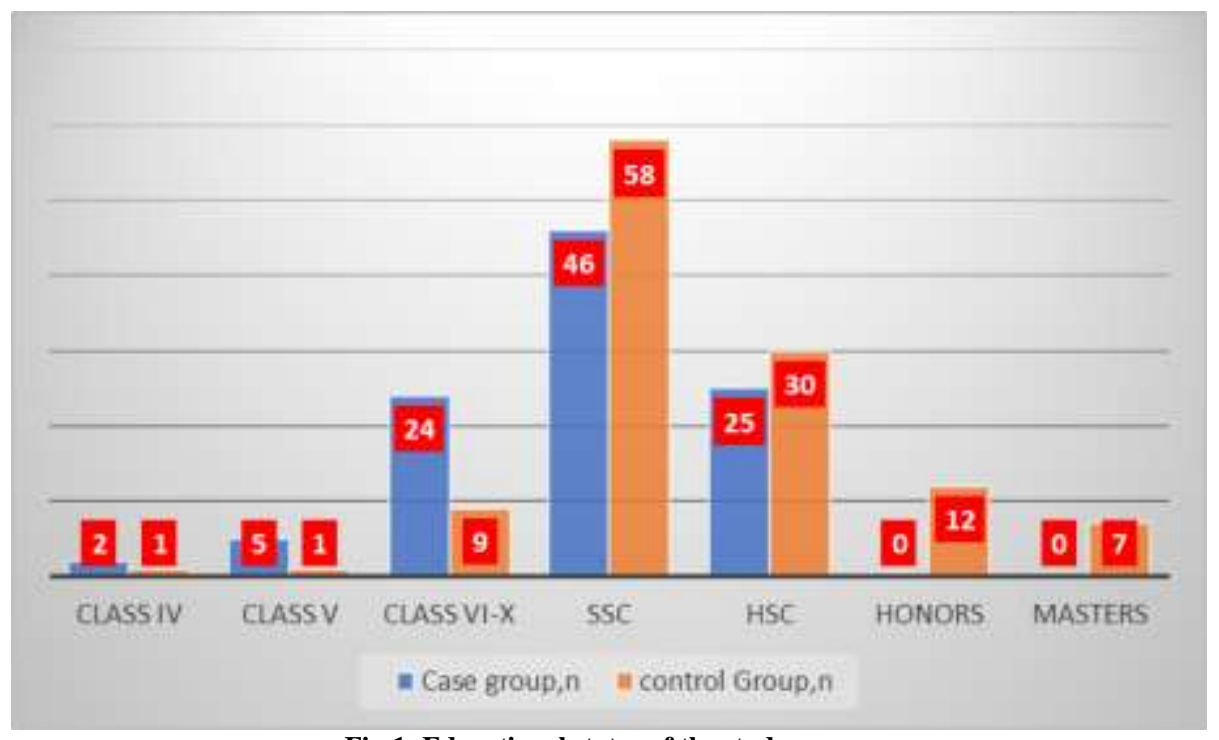

Fig-1: Educational status of the study group.

In figure-2 shows mode of delivery in case group where $23 \%$ had vaginal deliveries whereas $77 \%$ cases had caesaren deliveries. The following figure is given below in detail: 


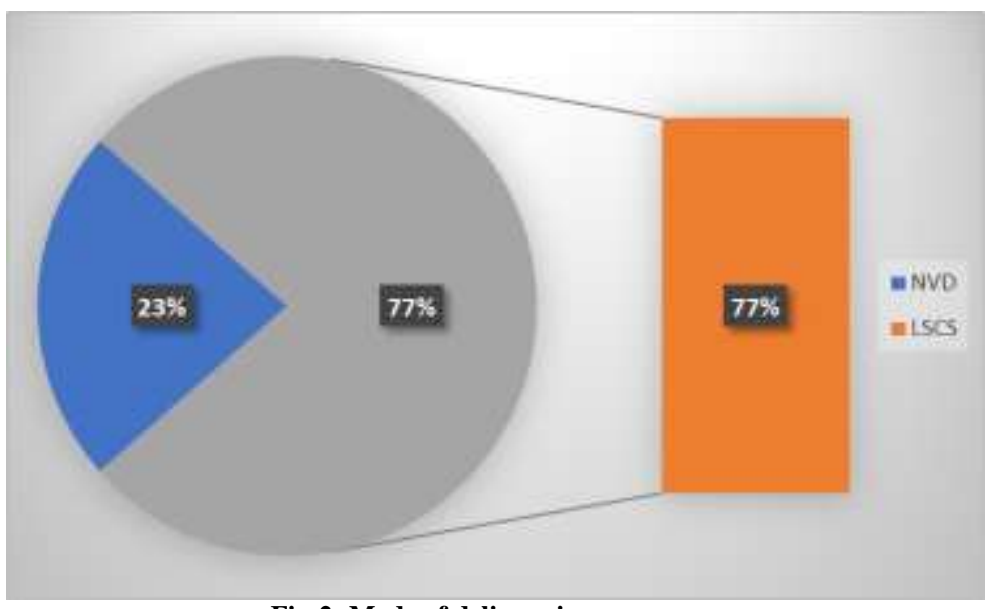

Fig-2: Mode of delivery in case group.

In table-2 shows complications associated with teenage pregnancy, where failed induction was common in case and control group, $14.5 \%$ and $9.25 \%$. The following table is given below in detail:

Table-2: Complications associated with teenage pregnancy

\begin{tabular}{|l|l|l|l|}
\hline \multicolumn{1}{|c|}{ Variable } & Case $(\mathbf{n = 1 0 0})$ & Control $(\mathbf{n = 1 1 8})$ & P value \\
\hline GDM & $3(1.4 \%)$ & $16(7.3 \%)$ & 0.007 \\
\hline PIH & $8(3.7 \%)$ & $12(5.5 \%)$ & 0.643 \\
\hline Eclampsia & $1(0.5 \%)$ & 0 & 0.459 \\
\hline Pre term labour & $9(4.1 \%)$ & $5(2.3 \%)$ & 0.175 \\
\hline Postdated pg & $6(3.3 \%)$ & $16(7.3 \%)$ & 0.630 \\
\hline Failed induction & $31(14.5 \%)$ & $20(9.2 \%)$ & $<0.001$ \\
\hline
\end{tabular}

In table-3 shows neonatal outcome where in case group $12.8 \%$ neonates were suffered from fetal distress, where as in control group it was $9.2 \%$. The following table is given below in detail:

Table-3: Neonatal outcome

\begin{tabular}{|c|c|c|c|}
\hline Neonatal outcome & Case & Control & P value \\
\hline Fetal distress & $28(12.8 \%)$ & $20(9.2 \%)$ & 0.071 \\
\hline Perinatal death & $2(0.9 \%)$ & $3(1.4 \%)$ & 0.578 \\
\hline Fetal weight & $2.83 \pm 0.385$ & $3.27 \pm 0.337$ & $<0.001$ \\
\hline NICU admission & $18(8.3 \%)$ & $14(6.4 \%)$ & 0.250 \\
\hline
\end{tabular}

In figure-3 shows indications of caesarean delivery in teenage pregnancy where failed induction is in teenage pregnancy with 31 cases and eclampsia and fetal distress contributing to 24 and 28 cases each. the following figure is given below in detail:

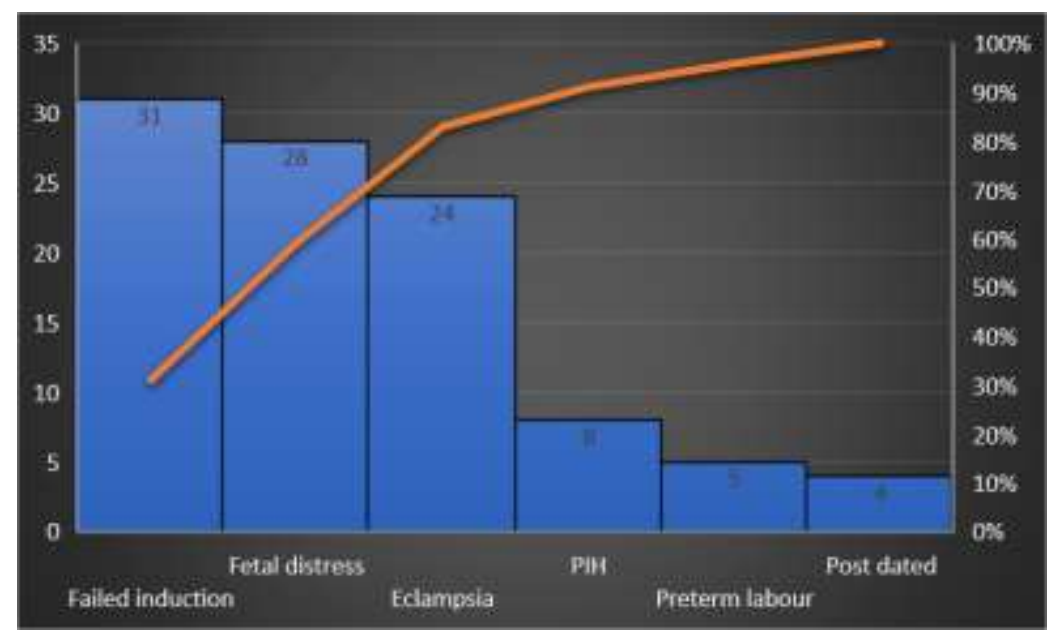

Fig-3: Indications of caesarean delivery in teenage pregnancy 


\section{DISCUSSION}

In our study we found that, adverse outcome of teenage pregnancy arises not only from physical and medical causes associated but also depends on individual, family, social, cultural, economic factors besides lack of access to health care resources, contraception, education.

Increased incidence of LSCS in teenage pregnancies and medical complications associated with it like anemia, PIH, and fetal complications being, prematurity, IUGR, Low birth weight are preventable factors [6].

In one study reported that, teenage pregnancy exposes mothers to many health-related complications and newborns to poor birth outcome. Adverse outcome of teenage pregnancy arises not only from physical and medical causes associated but also depends on individual, family, social, cultural, economic factors besides lack of access to health care, contraception, resources, education[7]. In our study we noted that, in case group most of the patients completed only their SSC, no one completed their masters where as in control group 7 people completed their masters. This implies that teenage mothers are less careful about their pregnancy probably secondary to lack of awareness, maturity and other social factors.

In one study reported that, increased incidence of LSCS in teenage pregnancies and medical complications associated with it like anemia, PIH, and fetal complications being, prematurity, IUGR, Low birth weight are preventable factors [8]. In our study we found that, $23 \%$ had vaginal deliveries whereas $77 \%$ cases had caesaren deliveries. Which similar to other studies.

Teenage pregnancy remains major health issue in our country due to prevailing social dogmas, age old traditions and poor access to health care in remote rural areas, illiteracy leads to lack of knowledge about family planning and puts the adolescents at risk for early pregnancy. Education play major role in decreasing the incidence of teenage pregnancy and its attendant health risks and psychological issues.

Rate of caesarean delivery was high, predominant indication being cephalo pelvic disproportion, fetal distress, medical disorders associated like pre-eclampsia, and eclampsia. Vaginal delivery was seen in cases with low birth weight baby's secondary to growth restriction or prematurity [9]. In our study we found that, in case group $12.8 \%$ neonates were suffered from fetal distress, where as in control group it was $9.2 \%$.

In teenage pregnancy where failed induction is in teenage pregnancy with 31 cases and eclampsia and fetal distress contributing to 24 and 28 cases each. Significant number of neonates born to teenage mothers had low birth weight, probably due to malnutrition, medical diseases associated with pregnancy leading to intrauterine growth restriction and prematurity [9].

\section{Conclusion}

From our study we can say that, in order to improve the teenage health periodic information, education, community activities, ANC camps to be held at primary health care centers. Further study is needed for better outcome.

\section{REFERENCE}

1. Doddihal CR, Katti SM, Mallapur MD. Teenage pregnancy outcome in a rural area of south India. Int J MedPublic Health.2015;5(3):222-4.2.

2. WHO, United Nations population fund: Married adolescents: no place of safety, Geneva: WHO, UNFPA; 2006.

3. Adolescent pregnancy-Issue in adolescent health and development; WHO discussion paper on adolescentsWHO; 2004:86. Available at http://apps.who.int/iris/bitstream/10665/42903/1/92 41591455_eng.pdf.

4. Allan Guttmachu institute. Risks and realities of earlychild bearing. Allan Guttmachu. 2000

5. UNICEF. A league table of teenage birth in rich nation. Innocenti Report Card. Florence, Italy. 2001; 3. Available at https://www.unicefirc.org/publications/pdf/repcard3e.pdf

6. Government of india, National family health survey. 2005-2006:3-24. Available at http://dhsprogram.com/pubs/pdf/FRIND3/FRIND3 -VollandVol2.pdf

7. Talawar S, Venkatesh G. Outcome of teenage pregnancy. IOSR JDental Med Sci. 2013;6(6):81-3.

8. Mukhopadhyay P, Chaudhuri RN, Paul B. Hospital-based perinatal outcomes and complications in teenage pregnancy in India. JHealth, Population Nutrition. 2010:28(5)|:494500 .

9. Kumar A, Singh T, Basu S, Pandey S, Bhargava V. Outcome of teenage pregnancy. Indian JPediatr. 2007;74(10):927-31. 